\title{
Patterns and Outcomes of Abdominal Trauma Patients Admitted to Trauma Intensive Care Unit
}

\author{
Seham Hassan Mohamed ${ }^{1}$, Mervet Anwer Abdel-Aziz ${ }^{2}$, Mogedda Mohamed Mehany ${ }^{3,}$ Naglaa Gamal Eldien \\ AbdElhafez ${ }^{4}$ \& Ahmed Talaat Ahmed Ali ${ }^{5}$ \\ 1. Assistant Lecturer of Critical Care Nursing \& Emergency, Faculty of Nursing, Sohag University, Egypt. \\ 2.\&3. Assistant Professor of Critical Care Nursing, Faculty of Nursing, Assuit University, Egypt. \\ 4. Lecture of Critical Care \& Emergency Nursing, Faculty of Nursing, Sohag University, Egypt. \\ 5. Lecturer of Anesthesiology and Intensive Care, Faculty of Medicine, Assuit University, Egypt
}

\begin{abstract}
Abdomen is the third most common area of the body that is damaged because of trauma. The nurse must be aware of specific assessment findings associated with abdominal trauma and immediate recognition of problems, so this study aimed to assess patterns and outcomes of abdominal trauma patients admitted to trauma intensive care unit.

A descriptive research design was used. Setting: This study was carried out in trauma intensive care unit at Assuit University Hospital. Sample: 60 adult critically ill patients with abdominal trauma. Tools: Patient profile characteristic's sheet and abdominal trauma severity scores and outcomes assessment sheet were used. Main results: There were $65 \%$ males and 35\% females. Mean Age was 36.62 \pm 10.8 . Blunt trauma accounted for $86.67 \%$ while penetrating was $13.33 \%$. Motor car accidents was the main cause of trauma with $51.67 \%$, liver and spleen the most affected organs. Mortality rate was 10\%. Gastrointestinal and respiratory complications are the most occurred. Conclusion: Abdominal trauma patients need frequent assessment as majority of the studied patients at a high risk for developing complications. Recommendations: Training the nurses about how to use abdominal trauma scoring systems for frequent assessment of patients' heath statue from first day of admission.
\end{abstract}

\section{Keywords: Abdominal Trauma, Intensive Care Unit, Outcomes \& Pattern.}

\section{Introduction}

Trauma (injury) has been defined as damage to the body caused by an exchange with environmental energy that is less than the body's resilience, (Panchal, \& Ramanuj, 2016) Abdomen is the third most common area of the body that is damaged because of trauma. Severe abdominal trauma is diagnosed in up to $20 \%$ of severe trauma patients and is associated with an increase in mortality rate up to 20\%, (Bouzat, et al., 2020). Some abdominal organs are damaged with a higher prevalence due to trauma. In addition to the mechanism of injury, it relays on size and location of the organs in the abdominal cavity, (Rajaei, et al., 2012).

Abdominal trauma can be classified basically into two types: penetrating (open) and blunt (closed). The penetrating referred to the entry of the aggressive objects into the peritoneal cavity occurs, in most cases a firearm projectile (gunshot) or a laminated object (stabbing) and it affects directly the viscera. The organs most affected in penetrating trauma are the small intestine, colon and liver, (Bordoni, et al., 2017) In total, main Causes of morbidity in abdominal penetrating trauma include: damages that are not detected, uncontrollable bleeding from the liver, spleen or large blood vessels rupture, and infection. And the major causes of morbidity are gastrointestinal perforation and peritonitis, (Abril et al., 2016) \& (Ohene, et al., 2010) Abdominal penetrating trauma includes sharp objects damage (stab wound) and gunshot damage (gunshot wound), (Gad, et al., 2012). The most common cause is the knife, (Rajaei, et al., 2012).

In blunt abdominal trauma there is no penetration of the aggressive agent into the peritoneal cavity. The effects of the offending agent in this case are transmitted to the viscera through the abdominal wall, or by kickback and deceleration. The prevalence of abdominal viscera lesions in cases of blunt trauma about $13 \%$, the spleen and liver being the most damaged structures in this type, (Nishijima, et al, 2012). Motor vehicle accidents account for 75 to 80 $\%$ of blunt abdominal trauma. Blunt injury of abdomen is also a result of fall from height, assault with blunt objects, sport injuries, and fall from riding bicycle, (Vanitha, 2018).

Symptoms of abdominal trauma include: Pain in abdomen, abdominal distension, vomiting, hematuria or retention of urine, bleeding per rectum, breathlessness or chest pain, discoloration, fullness in flanks, marked generalized distension, external signs of injury, absence of respiratory movements may indicate significant injury, : evidence of free fluid, (Panchal, \& Ramanuj, 2016). 
Risk factors for mortality must be identified and systematically studied in order to minimize the mortality in cases of abdominal trauma. Penetrating abdominal trauma can be easier and more reliable in diagnosis, whereas blunt abdominal trauma is often missed because clinical signs are less obvious, (Gad, et al., 2012).

The initial assessment and resuscitation of the abdominal trauma injured patient should follow the advanced trauma life support (ATLS) sequence of airway, breathing and circulation as airway compromise causes death within seconds, breathing derangement causes death within minutes and circulatory impairment causes death within hours, (Weledji, \& Tambe, 2018).

Outcomes of abdominal trauma are account for the majority of health problem and leading to hospitalization, long-term disability and death, (Challinor, et al., 2020) The most common complications of abdominal trauma are wound infection, wound dehiscence, burst abdomen, paralytic ileus, disseminated intravascular coagulopathy, (Maske, \& Deshmukh, 2016). Septicemia, pneumonia, hypovolemic shock, urinary tract infection, peritonitis, (Chalya, \& Mabula, 2013). Patients with an open abdomen stay long in hospital and in ICU, and this increases their hospital costs. Moreover, patients with an open abdomen are at risk of developing aspiration complications, pneumonia, pressure ulcers, acute respiratory failure, thromboembolism and an abdominal abscess, (Chipu, et al., 2017).

Every trauma victim requires a fast, correct and systematic assessment to immediately identify and treat life threatening injuries. Management of abdominal trauma requires, in particular, a transprofessional and multidisciplinary approach, begins from the Prehospital place to the intensive care unit (ICU), (Bouzat, et al., 2020).

Critical care nurses provide most of the direct care to patients in life threatening situations within intensive care units. Critical care nurses assess, plan, implement and evaluate health care services for patients suffering with a broad range of health conditions. Trauma victims and patients recuperating from complex surgeries frequently need nursing care of critically care specialists as well. Intensive care unit nurses work closely with physicians and other members of the health care team. They need to be skilled in the assessment of patients and able to use high technique equipment, (Efccna, 2007).

The critical care nurses play an important role in decreasing the incidence of unrecognized abdominal trauma by enhancing their knowledge and skills. They can achieve this by carrying out full and comprehensive physical assessments, and ensuring that members of the multidisciplinary team use the wide range of diagnostic adjuncts available to them, (Mcgrath \& Whiting, 2015).

Operational Definitions

Patterns: Refers to characteristics of abdominal trauma regarding type, mechanism, abdominal organs affected, associated extra- abdominal injuries and operative management of abdominal trauma patients included in the study.

Patient's outcomes: Includes Complications and length of ICU stay and patient condition at discharge either dies or still alive.

\section{Significance of the study}

Abdominal injuries are responsible for $10 \%$ of the mortalities due to trauma. Delays in early diagnosis or misdiagnoses are two major reasons for the mortality and morbidity associated with abdominal trauma, (Naeem, et al., 2018). Abdominal trauma is a serious problem in the world, due to its high prevalence in young people that affect economic status of the country, (Abril, et al., 2016). The nurse must be aware of specific assessment findings associated with abdominal trauma and immediate recognition of problems and prevention of occurrence complications, (Urden et al., 2018).

Aim of the study

To assess Patterns and outcomes of abdominal trauma patients admitted to trauma intensive care unit

Research questions

This study was directed to answer the following questions:

1. What are the patterns of abdominal trauma patients admitted to Trauma Intensive Care Unit?

2. What are the outcomes of abdominal trauma patients admitted to Trauma Intensive Care Unit?

Patient \& Methods

Research design:

A Descriptive research design used to conduct this study.

Setting

This study was carried out in trauma intensive care unit at Assuit university Hospital.

Sample

Sixty adult critically ill patients with abdominal trauma.

$$
\begin{aligned}
& n=\frac{\mathrm{N} \mathrm{Z}^{2} \sigma^{2}}{\mathrm{Z}^{2} \sigma^{2}+\mathrm{N}^{2}} \\
& \mathrm{n}=\frac{306 \times(1.96)^{2} \times(0.221)^{2}}{(1.96)^{2} \times(0.221)^{2}+306 \times(0.05)^{2}}=60
\end{aligned}
$$


Where:

$$
\begin{aligned}
& Z=1.96 \text { [standard scores] } \\
& e=0.05 \text { [error] } \sigma=0.221 \text { [SD], } \\
& \mathrm{N}=306 \text { [population], } \\
& \mathrm{n}=60 \text { [sample] }
\end{aligned}
$$

Dependent variable: Patients' outcomes.

Independent variable: Abdominal trauma patterns.

Inclusion criteria

- Age >18 years old.

- Newly admitted patient with abdominal trauma (blunt or penetrating)

- Patient with high injury severity score (ISS) > 15.

Exclusion criteria

- Pregnant women.

- Patients on a warfarin.

- Patients with chronic renal failure.

- Patient with previous history of abdominal diseases as (pancreatitis, liver diseases, malignancy).

Tools for data collection

Three tools were adopted by the researcher based on reviewing of the relevant literature and used to collect data pertinent to the study.

Tool I: Patient profile characteristics sheet:

It assessed the studied patients regarding the sociodemographic and medical related data as base line data; it includes two main parts as flowing:

Part one: demographic data: It covered the following areas

Demography of the patient include: Code, age, gender, date of admission and date of discharge.

Part two: Medical data which includes the following

- Past medical diseases, mechanism of abdominal trauma, type of abdominal trauma.

- Arterial blood gases parameters including PH, Pao2. Pco2, Hco3.

- Neurological examination: Glasgow Coma Scale that (developed by Green 2011). It is a neurological scale aims to give a reliable, objective way of recording the conscious level of a person for initial as well as subsequent assessment. It classified as:

- Severe, with GCS $\leq 8$

- Moderate, GCS 9 - 12

- Mild GCS $\geq 13$.

Acute Physiology and Chronic Health Evaluation II (APACHE II) scale: This tool adopted from (Naved et al., 2011), it was used to measure the severity of disease for adult patients admitted to ICU. APACHE II uses a point score based upon initial values of (12) routine physiologic measurements (internal temperature, heart rate, respiratory rate, oxygenation, arterial $\mathrm{pH}$, sodium, potassium, creatinine, hematocrit, white blood cells and Glasgow coma score), takes account of the patient's age, chronic health condition and physiological variables.

Second tool: Abdominal trauma severity tools: It consists of three parts

Part one: Injury Severity Score (ISS)

The Injury Severity Score (ISS) is adopted from (Pillai, et al., 2015) it is an anatomical scoring system that provides an overall score for patients with multiple injuries. The ISS consists of the result of the sum of the squares of the highest Abbreviated Injury score (AIS) scores for the three most severely different injured body regions. The six defined body regions for ISS are: head and neck, face, chest, abdominal and external. The ISS scores range from 1 to 75 , being one the least severe and 75 the most severe trauma injury. Any injury coded AIS 6 implies an ISS of 75.

Part two: Penetrating Abdominal Trauma Index. (PATI)

It is adopted from (Dogjani et al., 2016). It is a method of evaluating the risk of complications after penetrating abdominal trauma. A trauma index score was calculated by assigning a risk factor (1-5) to each organ injured and then multiplying this by a severity of injury estimate (1-5).The sum of the individual organ scores constituting the final penetrating abdominal trauma index (PATI).

- The sum of the individual organ scores comprised the final PATI. The range is 0-200

- The risk of postoperative complications increases in PATI scores greater than 25.

Part three: Blunt Abdominal Trauma Scoring System (BATSS)

It is adopted from (Shojaee, et al., 2014) It consists of 24-point, blunt abdominal trauma scoring system (BATSS) was developed and used to assess severity of injury. Patients were classified into three groups including low $($ score $<8)$, moderate $(8 \leq$ score $<12)$ and high risk (score $\geq 12)$. It was developed based on $\beta$ sums of following each factor:

(Blunt abdominal trauma scoring system)

\begin{tabular}{|l|c|}
\hline \multicolumn{1}{|c|}{ Item } & Score \\
\hline Abdominal pain & $\mathbf{2}$ \\
\hline Abdomen tenderness & $\mathbf{3}$ \\
\hline Chest wall sign & $\mathbf{1}$ \\
\hline Pelvic fracture & $\mathbf{5}$ \\
\hline FAST & $\mathbf{8}$ \\
\hline SBP $<100 \mathrm{mmHg}$ & $\mathbf{4}$ \\
\hline PR $>100$ beats/min & $\mathbf{1}$ \\
\hline Total & $\mathbf{2 4}$ \\
\hline
\end{tabular}


Third tool: Patients' outcomes tool

Part one: Melbourne score: It adopted from ( Li et al., 2018) .It assesses presence of postoperative pulmonary complications (PPC) as it the most common complication following surgery. PPC is defined in those patients presenting with four or more of the following eight Criteria. (4 of 8 factors) indicate postoperative pulmonary complications.

(Melbourne Group Scale (MGS)

\begin{tabular}{|c|}
\hline Criteria \\
\hline - Temperature $>38^{\circ} \mathrm{C}$ \\
\hline $\begin{array}{l}\text { - White cell count >11.2 or use of } \\
\text { respiratory antibiotics }\end{array}$ \\
\hline $\begin{array}{l}\text { - Physician diagnosis of pneumonia or } \\
\text { chest infection }\end{array}$ \\
\hline $\begin{array}{l}\text { - Chest X-ray findings of } \\
\text { atelectasis/consolidation }\end{array}$ \\
\hline $\begin{array}{l}\text { - Production of purulent (yellow/green) } \\
\text { sputum different from preoperative } \\
\text { sputum }\end{array}$ \\
\hline $\begin{array}{l}\text { - Positive results upon sputum } \\
\text { microbiological analysis }\end{array}$ \\
\hline - $\mathrm{SpO}_{2}<90 \%$ in ambient air \\
\hline $\begin{array}{l}\text { - prolonged HDU stay or readmission to } \\
\text { HDU or ITU }\end{array}$ \\
\hline
\end{tabular}

HDU, high dependency unit, ITU: intensive therapy unit, PPC: postoperative pulmonary Complications.

Part two: Outcomes assessment sheet:

It assesses presence of any complications as respiratory, cardiovascular, gastrointestinal, renal, wound complications, length of ICU stay, duration of mechanical ventilation and mortality.

\section{Methods}

This study was carried out through the following two phases:

Preparatory phase

- An official Permission was granted by the researcher from the head of trauma intensive care unit at Assuit university hospital after explanation of the aim and nature of the study.

- The tools used in this study were adapted by the researcher based on reviewing the relevant literature.

\section{Content validity}

The tools were tested for content related validity by 5 specialists in the field of critical care medicine and critical care nursing from Assuit and Sohag University

Pilot study

A pilot study was conducted on $10 \%$ of the study subjects to test the feasibility and applicability of the tools and time needed to collect the data. The tools were applicable. The pilot study subjects were excluded from the actual study.
Reliability of the tool was done using Cronbach's coefficient alpha score; it was 0.766

\section{Ethical considerations}

- The research protocol was approved from ethical committee from faculty of nursing.

- There was no risk for study subject during application of the research.

- The study followed common ethical principles in the clinical research.

- Written consent was obtained from patients or guidance that are willing to participate in the study after explaining the nature and purpose of the study.

- Patients were assured that the data of this research will be used only for the purpose of research.

- Confidentiality and anonymity were assured.

- Patients had the right to refuse to participate and/or withdraw from the study without any rational at any time.

Implementation phase

-The Purpose of the study was simply explained to patients and their relatives in case of patient loss of conscious.

-The researcher started to collect data from the first day of patients' admission to Trauma ICU.

-The study involved 60 patients who admitted to the Trauma Intensive Care Unit at Assuit University Hospital. In addition, the following data were collected on admission from the patients' files including the following.

- Demographic data of the patient which include: Code, age, gender, date of admission and date of discharge.

- Medical data which include past medical diseases, mechanisms of abdominal trauma, type of abdominal trauma.

- Glasgow Coma Scale monitoring.

- Acute Physiology and Chronic Health Evaluation II (APACHE II)

- Arterial blood gases parameters including PH, Pao2. Pco2, Hco3.

- Penetrating abdominal trauma index: (PATI) for patients with penetrating abdominal trauma.

- Blunt abdominal trauma scoring system (BATSS) for patients with blunt abdominal trauma.

Finally the researcher evaluated the studied patients' outcomes according to their assessment data on discharge, by recording the following:

- Melbourne score for assessment of postoperative pulmonary complications to whom patients undergoing abdominal surgery. 
- Complications evaluation: respiratory, cardiovascular, Gastrointestinal, renal and wound complications.

- $\quad$ Length of ICU stay.

- Duration of mechanical ventilation

- Mortality.

\section{Results}

Table (1): Percentage distribution of the studied sample in relation to the demographic data and APACHE II score $(\mathrm{N}=60)$.

\begin{tabular}{|l|c|c|}
\hline \multicolumn{1}{|c|}{ Socio-demographic } & \multicolumn{2}{|c|}{ Sample (N= 60) } \\
\cline { 2 - 3 } Sex & No. \\
\hline Male & 39 & 65.00 \\
\hline Female & 21 & 35.00 \\
\hline Age & \multicolumn{2}{|c|}{25.00} \\
\hline $18-29$ & 15 & 63.33 \\
\hline $30-49$ & 38 & 11.67 \\
\hline $50-60$ & 7 & $36.62 \pm 10.8$ \\
\hline Age: (years) Mean \pm SD & \multicolumn{2}{|c|}{$19.7 \pm 2.36$} \\
\hline APACHE II score at admission & \multicolumn{2}{|c|}{} \\
\hline
\end{tabular}

(APACHE II) Acute Physiology and Chronic Health Evaluation II

Table (2): Percentage distribution of the studied sample in relation to past medical history, type, mechanism of abdominal trauma patient and operative management $(\mathrm{N}=60)$.

\begin{tabular}{|l|c|c|}
\hline \multicolumn{1}{|c|}{ Clinical data } & \multicolumn{2}{c|}{ Sample (N= 60) } \\
\cline { 2 - 3 } & \multicolumn{2}{c|}{ No. } \\
\hline Past medical history & 19 & 31.67 \\
\hline Yes & 41 & 68.33 \\
\hline No & \multicolumn{2}{c}{} \\
\hline Type of abdominal trauma & 52 & 13.33 \\
\hline Blunt & 8 & 51.67 \\
\hline Penetrating & & 25 \\
\hline Mechanism of abdominal trauma & 31 & 13 \\
\hline Motor car accident & 15 & 6.67 \\
\hline Falling from height & 8 & 3.33 \\
\hline Assault & 4 & \\
\hline Gun shot & 2 & \\
\hline surgical fault & & \\
\hline Operative management & 42 & \\
\hline Yes & 18 & \\
\hline No & & \\
\hline
\end{tabular}


Table (3): Distribution of mean score of the study sample according to arterial blood gases parameters at admission and discharge $(\mathrm{N}=60)$.

\begin{tabular}{|c|c|c|c|c|c|}
\hline \multirow{2}{*}{ Arterial blood gases } & \multirow{2}{*}{\multicolumn{2}{|c|}{$\begin{array}{c}\text { Admission } \\
\text { Mean } \pm \text { SD }\end{array}$}} & \multirow{2}{*}{\multicolumn{2}{|c|}{$\begin{array}{c}\text { Discharge } \\
\text { Mean } \pm \text { SD }\end{array}$}} & \multirow{3}{*}{$\begin{array}{r}\text { P-value } \\
0.054\end{array}$} \\
\hline & & & & & \\
\hline $\mathrm{PH}$ & 31.7 & \pm 0.09 & 7.34 & \pm 0.05 & \\
\hline Pao2 & 25.37 & \pm 6.79 & 26.35 & \pm 8.46 & 0.000 \\
\hline $\mathrm{Pco} 2$ & 51.52 & \pm 15.99 & 43.60 & \pm 10.36 & 0.002 \\
\hline $\mathrm{Hco} 3$ & 23.45 & \pm 4.78 & 21.48 & \pm 3.80 & 0.010 \\
\hline
\end{tabular}

Dependent samples t-test $\quad P>0.05$ non-significant $\quad P<0.05$ significant

Table (4): Distribution of the study sample in relation to mean of Glasgow coma scale (GCS) At admission and discharge $(\mathrm{N}=60)$.

\begin{tabular}{|c|c|c|c|c|c|}
\hline \multirow{4}{*}{ Glasgow Coma Scale } & \multirow{2}{*}{\multicolumn{2}{|c|}{$\begin{array}{c}\text { Admission }(n=60) \\
\text { Mean } \pm \text { SD }\end{array}$}} & \multirow{2}{*}{\multicolumn{2}{|c|}{$\begin{array}{c}\text { Discharge } \\
\text { Mean } \pm \text { SD }\end{array}$}} & \multirow[b]{2}{*}{$P$ value } \\
\hline & & & & & \\
\hline & 11.73 & \pm 1.69 & \multicolumn{2}{|c|}{$2.26 \pm 12.60$} & \multirow{5}{*}{0.020} \\
\hline & $\mathbf{N}$ & $\%$ & $\mathbf{N}$ & $\%$ & \\
\hline Mild (13-15) & 18 & 30 & 38 & 63.33 & \\
\hline Moderate (9-12) & 41 & 68.33 & 17 & 28.33 & \\
\hline Severe 8 or less & 1 & 1.67 & 5 & 8.33 & \\
\hline
\end{tabular}

Chi-square test

$P>0.05$ non-significant

$P<0.05$ significant

Table (5): Mean distribution of the study sample according to ISS, BATSS and PATI (N=60).

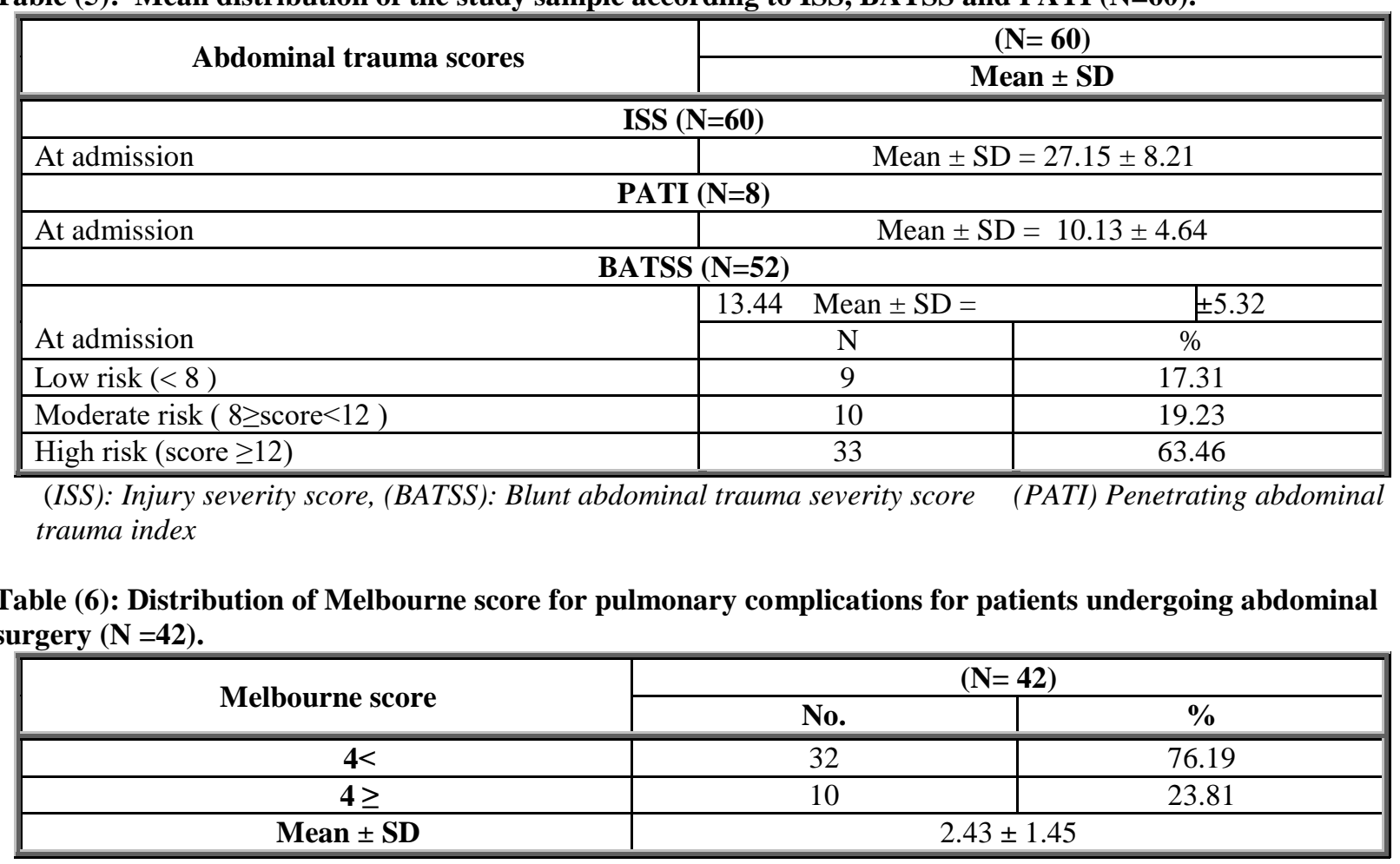


Table (7): Distribution of percentage regarding presence of systemic complications $(\mathrm{N}=60)$.

\begin{tabular}{|c|c|c|}
\hline \multirow{2}{*}{ Complications } & \multicolumn{2}{|c|}{$(\mathrm{N}=60)$} \\
\hline & No. & $\%$ \\
\hline \multicolumn{3}{|l|}{ Respiratory complications: } \\
\hline Acute respiratory distress syndrome & 9 & 15.00 \\
\hline Pneumonia & 11 & 18.33 \\
\hline \multicolumn{3}{|l|}{ Cardiovascular complications: } \\
\hline Thromboembolism & 1 & 1.67 \\
\hline Shock & 14 & 23.33 \\
\hline \multicolumn{3}{|l|}{ Gastrointestinal complications: } \\
\hline GIT bleeding & 5 & 8.33 \\
\hline Peptic ulcer & 13 & 21.67 \\
\hline Constipation & 28 & 46.67 \\
\hline Diarrhea & 7 & 11.67 \\
\hline Vomiting & 22 & 36.67 \\
\hline Distention & 4 & 6.67 \\
\hline \multicolumn{3}{|l|}{ Renal complications: } \\
\hline Acute kidney injury & 3 & 5.00 \\
\hline Urinary tract infection & 5 & 8.33 \\
\hline \multicolumn{3}{|l|}{ Wound complications } \\
\hline Wound dehiscence & 1 & 1.67 \\
\hline Wound infection & 7 & 11.67 \\
\hline
\end{tabular}

Table (8): Distribution of outcomes regarding mortality rate, ICU stay and MV duration (N=60).

\begin{tabular}{|c|c|c|}
\hline \multirow{2}{*}{ Outcomes } & \multicolumn{2}{|c|}{ Sample $(N=60)$} \\
\hline & No. & $\%$ \\
\hline Mortality & 6 & 10.00 \\
\hline \multirow{2}{*}{ ICU stay } & \multicolumn{2}{|c|}{ Mean \pm SD $=16.73 \pm 4.47$} \\
\hline & No. & $\%$ \\
\hline$<15$ & 21 & 35 \\
\hline $15-20$ & 29 & 48.33 \\
\hline$>20$ & 10 & 16.67 \\
\hline \multirow{2}{*}{ Duration of mechanical ventilation } & \multicolumn{2}{|c|}{ Mean \pm SD $=11.90 \pm 4.40$} \\
\hline & No. & $\%$ \\
\hline$<15$ & 46 & 76.67 \\
\hline $15-20$ & 12 & 20 \\
\hline$>20$ & 2 & 3.33 \\
\hline
\end{tabular}

Table (9): Relation between patients criteria and complications $(\mathrm{N}=60)$.

\begin{tabular}{|c|c|c|c|c|c|c|c|}
\hline \multicolumn{2}{|c|}{$\begin{array}{ll}\text { Admission } & \text { Complications } \\
\text { Criteria } & \end{array}$} & $\begin{array}{c}\text { Respiratory } \\
\%\end{array}$ & $\begin{array}{c}\text { Cardiovascu } \\
\text { lar\% }\end{array}$ & $\begin{array}{l}\text { Gastroint } \\
\text { estinal \% }\end{array}$ & Renal\% & $\begin{array}{c}\text { Wound } \\
\text { infection \% }\end{array}$ & $P$.value \\
\hline \multirow{3}{*}{ Age } & $18-29(\mathrm{~N}=15)$ & 13.33 & 33.33 & 100.00 & 13.33 & 20.00 & \multirow{3}{*}{0.034} \\
\hline & $30-49(\mathrm{~N}=38)$ & 28.95 & 23.68 & 92.11 & 10.53 & 7.89 & \\
\hline & $50-60(\mathrm{~N}=7)$ & 100.00 & 14.29 & 28.57 & 28.57 & 28.57 & \\
\hline \multirow{2}{*}{ Sex } & Male $\quad(\mathrm{N}=39)$ & 25.64 & 30.77 & 87.18 & 7.69 & 15.38 & \multirow{2}{*}{0.187} \\
\hline & Female $\quad(\mathrm{N}=21)$ & 47.62 & 14.29 & 85.71 & 23.81 & 9.52 & \\
\hline \multirow{3}{*}{ GCS } & Mild $\quad(\mathrm{N}=18)$ & 33.33 & 33.33 & 94.44 & 5.56 & 11.11 & \multirow{3}{*}{0.927} \\
\hline & moderate $(\mathrm{N}=41)$ & 34.15 & 21.95 & 82.93 & 17.07 & 14.63 & \\
\hline & Sever $\quad(N=1)$ & 0.00 & 0.00 & 100.00 & 0.00 & 0.00 & \\
\hline \multirow{2}{*}{$\begin{array}{c}\text { Past } \\
\text { medical } \\
\text { history }\end{array}$} & $(\mathrm{N}=19)$ & 26.32 & 31.58 & 78.95 & 10.53 & 15.79 & \multirow{2}{*}{0.863} \\
\hline & $(\mathrm{N}=41)$ & 36.59 & 21.95 & 90.24 & 14.63 & 12.20 & \\
\hline
\end{tabular}

Chi-square test $\quad P>0.05$ non-significant $\quad P<0.05$ significant 


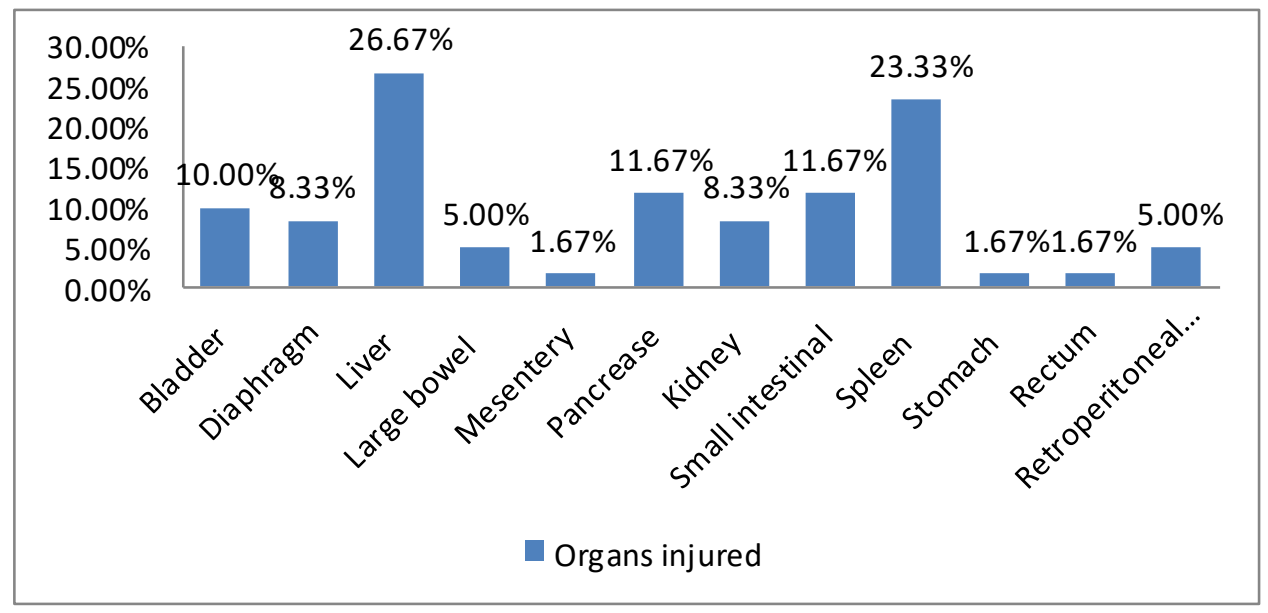

Figure (1): Percentage distribution of the study sample in relation to specific organs injury $(\mathrm{N}=60)$.

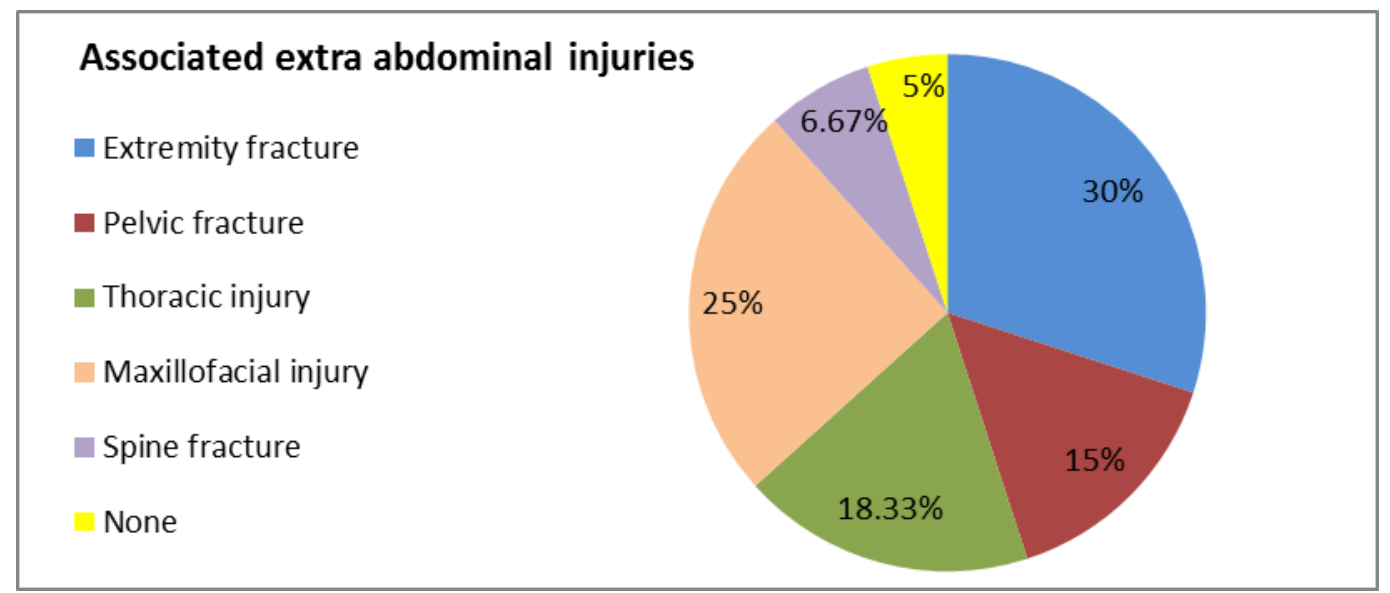

Figure (2): Percentage distribution of the study sample in relation to associated extra abdominal injuries $(\mathrm{N}=60)$.

Table (1): Shows that more than half of the study sample were males, aged from 30- 49 years old. In addition, APACHE II SCORE for patient at admission was $(19.7 \pm 2.36)$

Table (2): Shows that the majority of the study sample had no past medical history and had blunt abdominal trauma $(68.33 \%$ and $86.67 \%$ ) respectively. In addition, the table illustrated that regarding the mechanism of abdominal trauma that majority had motor car accidents and falling from height $(51.67 \%$ and $25 \%$ ) respectively. In relation to operative management the table showed that the majority was (70\%) undergoing surgery.

Table (3): Concerning the arterial blood gases parameters, this table exhibits significant difference between admission and discharge regarding Pao2, $\mathrm{Paco} 2$ and $\mathrm{Hco} 3$ in the studied patient with $\mathrm{P}$. value (0.000), (0.002) \& (0.010) respectively. While PH shows no significant difference with $\mathrm{P}$ value at (0.054).

Table (4): Shows that regarding Glasgow coma scale, there was highly statistical significant difference between admission and discharge with $\mathrm{P}$ value (0.020).

Table (5): Shows that the mean of Injury Severity score at admission was $(27.15 \pm 8.21)$. While penetrating abdominal trauma index and Blunt abdominal trauma severity score the mean was (10.13 \pm 4.64 and $13.44 \pm 5.32$ ) respectively. Regarding risk of blunt abdominal trauma, the majority of cases had high risk score $(63.46 \%)$.

Table (6) Demonstrates that the mean of Melbourne score was $(2.43 \pm 1.45)$ and about quarter of the postoperative cases developed postoperative pulmonary complications $(23.81 \%)$.

Table (7): Shows that the majority of the sample had developed gastrointestinal, pulmonary, cardiovascular complications respectively.

Table (8): Illustrates the outcomes of the studied patients according to their assessment data on discharge. It was found that $10 \%$ of patients were died. Regarding length of ICU stay, about half $(48.33 \%)$ of the studied sample stayed between (15 20) days and low percent stayed more than 20 days 
(16.67\%) with mean length of stay $(16.73 \pm 4.47)$. The table also shows the duration of mechanical ventilation of the studied patients, it was found that the majority of the studied sample ( $76.67 \%$ ) stayed (<15) days on MV and low percent stayed more than 20 days $(3.33 \%)$ with mean length of stay (11.90 \pm 4.40)

Table (9): Shows statistical significant difference between age and complications with $\mathrm{P}$ value (0.034).

Figure (1): Shows that the majority of the study sample had liver, spleen, small intestine, pancreatic and bladder injury with percentage $(26.67 \%, 23.33 \%$ $, 11.67 \%, 11.67 \%$ and $10 \%$ ) respectively.

Figure (2): Shows the majority of the study sample had extra-abdominal injuries represented in extremity fracture, maxillofacial injury and thoracic injury with percentage $(30 \%, 25 \%$ and $18.33 \%)$ respectively.

\section{Discussion}

Trauma is still the main cause of a significant number of emergency admissions globally. Abdominal trauma leading to marked morbidity and mortality of trauma patients, (Arumugam, et al., 2015). About one-third of all trauma patients have abdominal injuries. These injuries require careful triaging for appropriate interventions and care, (Ntundu, et al., 2019).

Regarding description of current study sample, the result revealed that study sample included 60 traumatic abdominal trauma patients who were admitted to Trauma intensive care unit. Numbers of males constituted more than half of the sample and aged (30-49). High percentage of males and this age group may be because they have more freedom and more outdoor activities and they are the most productive age groups of society suggesting huge economic loss to the country related to their injuries. These results were supported with Behboodi, et al., (2016) who reported that from 180 patients, the majority were males included within his study, but It comes in contrast with the study done by Olaogun, et al., (2018) when assessed abdominal trauma in a semi-urban tertiary health institution, who revealed that less than half of the sample aged (30 -50) years old. The mean age of the current study supported with the study done by Alqarafi, et al., (2019) when assessed "The patterns of abdominal trauma and factors associated with ICU admission in a major trauma center in Medina".

Regarding APACHE II score, the mean of the current study was more than the study done by Dossett, et al., (2009) when evaluated "Revising the validity of APACHE II in the trauma ICU; risk stratification in critically injured adults"

Regarding previous medical history, the current study documented that the majority (about two thirds) of the study sample had no past medical history. Absence of past medical diseases may be related to that most of the study sample aged less than fifty years old. This result were supported with Alqarafi et al., (2019) who cleared that most of cases had no past medical history.

Regarding type of abdominal trauma, the current study revealed that the major sample had blunt abdominal trauma. This may be related to that the majority of abdominal trauma were resulting from motor car accidents and falling from height. This result was supported with study by Panchal \& Ramanuj (2016) when assessed "The study of abdominal trauma: patterns of injury, clinical presentation, organ involvement and associated injury" and reported that blunt abdominal trauma was the most common type. Our results disagreed with Idriss et al., (2018) when evaluated "Abdominal Trauma: Five years' experience in National Centre Hospital, Mauritania" as this study showed that penetrating abdominal trauma was dominant.

Concerning mechanism of injury, our study revealed that the high percentage (about half) was pointed to motor car accidents and this may be related to careless driving, speed violation, brake failure, traffic violations, faulty overtaking, burst tire, bad roads and alcohol use. This result disagreed with the study by Idriss et al., (2018) reported that stab injuries was the dominant. Our results comes in line with the study done by Alqarafi et al., (2019) which indicate that motor car accidents were the most common cause of abdominal trauma.

Regarding operative management, our study revealed that the majority undergoing surgical intervention. This may be resulting from increased severity of the injury and the surgery will save the victim life and prevent further complications. Olaogun, et al., (2018) agreed with our results and cleared that majority of study had operative management.

Concerning presence of associated injuries: according to the present percentages of current results, it is important to keep in mind that every abdominal trauma patient should be thoroughly evaluated for others trauma or injury whether there is any obvious signs is present or not. The present study illustrated that the highest percentage of the study sample had extremities fractures. That extremities fractures resulting from that the major cause of trauma in our study was motor car accident and falling from height .Our result not supported with the study by Panchal \& Ramanuj (2016) who cleared that thoracic injury is the most common associated injury.

Concerning affected organs with injury, the present study illustrated that liver and spleen were the most affected organs. The main cause that spleen and liver are the most two commonly injured organs in various forms of abdominal trauma because of their relative 
size, relatively fixed positions and abundant vascular supply which make them prone both to injury, (Malaki \& Mangat, (2011). Our result was supported with Alqarafi et al., (2019) as the study revealed that liver and spleen the most affected organs.

Regarding level of conscious represented in Glasgow coma scale, the present study cleared that more than half of the study sample had moderate conscious level at admission. Moderate level of conscious may be related to most of patients had severe injuries. Our result contrasted with study done by Gad et al., (2012) in their study about "Incidence, Patterns, and Factors Predicting Mortality of abdominal Injuries in Trauma Patient" indicated that majority of the sample had high conscious level.

Regarding Injury severity score the current study showed that patients had high score at admission. High injury severity score was related to that the cases had a major trauma and the patient had more than one organ injured. This result is matching with study done by Gad et al., (2012). Concerning Blunt abdominal trauma scoring system (BATSS), the current results showed that more than half of study sample at high risk for development complications and need further observation from ICU staff. This result is supported with study done by Shojaee et al., (2014) who evaluated "New scoring system for intraabdominal injury diagnosis after blunt trauma all high risk patients" indicated that patient with high BTASS suffered intra-abdominal injuries and need medical or surgical care. Regarding Penetrating abdominal trauma index (PATI), our study revealed that the mean was the same to the study done by Agron et al., (2016) when evaluated "Severity Score, as predictive factors in management of Penetrating abdominal Trauma".

Regarding Melbourne score for pulmonary complications for patients undergoing abdominal surgery, our study showed that near quarter of the postoperative cases had score $(>4)$ and also indicated presence of postoperative pulmonary complications (PPC) and this was clear when evaluated patients' outcomes. Our result comes in line with Agostini et al., (2011) who indicated that The MGS (Melbourne group scale) best corresponds with the clinical outcome diagnosis of PPC.

Regarding presence of complications, the results showed that majority of the cases developed gastrointestinal complications specially constipation which constituted about half of the cases. This may be related to diet regimen at ICU and limitation of mobility of the patient and the nature of trauma which affected mostly GIT. The second most common complications were respiratory complications as the diaphragm and abdominal muscles play an important role in the process of respiration. Pneumonia and acute respiratory distress syndrome were the most common respiratory complications as the majority of the patients stay long at ICU and exposed to mechanical ventilation. Manohar \& Ramanaiah (2015) in the study of "Abdominal Trauma in adults its outcome - a prospective study in a teritiary health care centre in Andhra Pradeshah", the study enumerated complications as highest percentage pointed to surgical site infection and hypovolemic shock.

Regarding outcomes; the current study revealed that mean of ICU stay was more than the mean of stay done with Alqarafi et al., (2019). The cause of increase length of the stay in our study that the most of patients had severe injuries and required more care. Also this study indicated that (10\%) were died while in study by Ntundu et al., (2019) when evaluated "Patterns and outcomes of patients with abdominal trauma on operative management from northern Tanzania: a prospective single center observational study" showed that the mortality rate was $(13.2 \%)$.

Regarding relation between patients' criteria and complications, our study revealed that high percentage of complications affected patients aged (50-60), as the old patients are the most susceptible age group for developing complications during hospitalization.

\section{Conclusion}

Based on the findings of the present study, it can be concluded that the majority of patients with abdominal trauma admitted to trauma intensive care unit is greatest in young adult males. Blunt trauma is highly in occurrence compared to penetrating trauma. The main mechanism of injury is motor car accidents. The liver and spleen are the most affected abdominal organs. The associated musculoskeletal injuries are the most associated extra-abdominal injuries. Gastrointestinal and pulmonary complications represented the majority of complications in ICU. This study highlights the patterns and characteristics for those patients and describes their outcomes after course of ICU stay. The nurse must be aware of specific assessment findings associated with abdominal trauma and immediate recognition of problems and prevent occurrence of complications to patients admitted to ICU.

\section{Recommendations}

Future similar studies should be carried on a large sample size in different governmental hospitals to reveal patterns of abdominal trauma 
- Developing strategies that necessitate training the nurses on how to use abdominal trauma scoring systems for frequent assessment of patients' heath statue from first day of admission to prevent further complications.

\section{References}

1. Abril B., Vahdati S., Paknezhad S., Majd P., \& Bahrami M., (2016): Abdominal penetrating trauma and organ damage and its prognosis, J Anal Res Clin Med, vol.(4), No.(4), pp. 203-6.

2. Agostini P., Naidu B., Cieslik H., Rathinam S., Bishay E., Kalkat M., Rajesh P., Steyn R., \& Singh S., (2011): Comparison of recognition tools for postoperative pulmonary complications following thoracotomy, Physiotherapy vol.(97), no.(4), pp.278-83.

3. Agron D., Eliziana P., Engjellushe J., Blenarda1 H., \& Najada K., (2016): PATI Index \& Injury Severity Score, as predictive factors in management of Penetrating abdominal Trauma, poster, $17^{\text {th }}$ Eurpean Congress of Trauma \& Emergency Surgery.

4. Alqarafi A., Alhazmi A., Alawfi A., Alruhaili E., Alebrahaimi F., \& Sebeih S., (2019): The patterns of abdominal trauma and factors associated with ICU admission in a major trauma center in Medina [AMJ vol. (12), no.(3), pp.71-80.

5. Arumugam S., Al-Hassani A., El-Menyar A., Abdelrahman H., Parchani A., Peralta R., Zarour A., \& Al-Thani H., (2015): Frequency causes and pattern of abdominal trauma: a 4-year descriptive analysis. J Emerg Trauma Shock, Vol.(8), no.(4), pp.193 - 198.

6. Behboodi F., Amiri Z., Masjedi N., Shojaie R., \& Sadri P., (2016): Outcome of Blunt Abdominal Traumas with Stable Hemodynamic and Positive FAST Findings, Emergency, vol.(4), no.(3), pp. 136-139.

7. Bordoni P., Santos D., Teixeira J., \& Bordoni L., (2017): Deaths from abdominal trauma: analysis of 1888 forensic autopsies, Rev Col Bras Cir vol.(44), no.(6), pp.582-595.

8. Bouzat P., Valdenaire G., Gauss T., Charbit J., Arvieux C., Balandraud P., Bobbia X ., David J., Frandon J., Garrigue D., Long J., Pottecher J., Prunet B., Simonnet B., Tazarourte K., sallet C., Vaux J., Viglino D., Villoing B., Zieleskiewicz L., Gil-Jardine C., \& Weiss E., (2020): Early management of severe abdominal trauma, Anaesth Crit Care Pain Med, vol.(39), no.(2), pp.269-277.

9. Challinor K., Kidd M., \& Pitcher R., (2020): How useful are clinical details in blunt trauma referrals for computed tomography of the abdomen?, SA J Radiol; 24(1): 1837.

10. Chalya P., \& Mabula J., (2013): Abdominal trauma experience over a two-year period at a tertiary hospital in north- western Tanzania: a prospective review of 396 cases, Tanzania Journal of Health Research Doi, Vol.(15), No. (4), pp. 1-13.

11. Chipu M., Kearns I., \& Nel W., (2017): Experiences of registered nurses caring for patients with an open abdomen in an intensive care unit in Gauteng, HEALTH SA GESONDHEID, Vol.(22), pp. 166-173.

12. Dogjani A., Petrela E., Jonuzi E., \& Blenarda H., (2016): PATI Index \& Injury Severity Score, as predictive factors in management of Penetrating abdominal Trauma, Eur J Trauma Emerg Surg, vol.(42), Suppl. (2), pp.S9-S245.

13. Dossett L., Redhage L., Sawyer R., \& May A., (2009): Revising the validity of APACHE II in the Ttauma ICU; risk stratification in critically injured adults, Injury, vol.(40), no.(9), pp. 993-998.

14. Efccna, (2007): Position Statement on workforce requirements within European Critical Care Nursing 2007. Retrieved February, 5.2011 from http://www.efccna.org/downloads/Position\%2 OState.pdf

15. Gad M., Saber A., Farrag S., Shams M., \& Ellabban G., (2012): Incidence, Patterns, and Factors Predicting Mortality of Abdominal Injuries in Trauma Patient, North American Journal of Medical Sciences Vol.(4), Issue (3) , pp. $129-134$

16. Green M., (2011) Cheerio, Laddie! Bidding Farewell to the Glasgow Coma Scale Steven, Annals of Emergency Medicine, vol. (58), No (5), pp.427-430.

17. Idriss A., Baba T., Boukhary S., Hamad B., Abdllatif M., Kane T., Abdllahi M., Moctar B., \& Taleb B., (2018): Abdominal Trauma: Five Years Experience in National Centre Hospital, Mauritania, Open Journal of Emergency Medicine, vol. (6), no. (1), pp. 614.

18. Li X., Chen C., Wei X., Zhu Q., Yao W., Yuan D., Luo G., Cai J., \& Hei Z., (2018): Retrospective Comparative Study on Postoperative Pulmonary Complications After Orthotopic Liver Transplantation Using the Melbourne Group Scale (MGS-2) Diagnostic Criteria, Annals OF Transplantation, vol. (23), pp. 377-386. 
19. Malaki M., \& Mangat K., (2011): Hepatic and splenic trauma, Trauma, vol.(13), no.(3), pp. 233-244

20. Manohar K., \& Ramanaiah V., (2015): in the study of "Abdominal Trauma in adults - its outcome - a prospective study in a teritiary health care centre in Andhra Pradeshah, Indian Journal of Applied Research, vol.(5) Issue (11), pp. 35 - 38.

21. Maske A., \& Deshmukh S., (2016): Traumatic abdominal injuries: our experience at rural tertiary care center, Int Surg J, vol. (3), no.(2), pp.543-548.

22. Mcgrath A., \& Whiting D., (2015): Recognising and assessing blunt abdominal trauma, |Emergency Nurse, Vol. (22), no. (10), pp. $18-24$.

23. Naeem B., Perveen S., Naeem N., Ahmed T., Khan I., Khan I., Tahir M., \& Iqbal M., (2018): Visceral Injuries in Patients with Blunt and Penetrating Abdominal Trauma Presenting to a Tertiary Care Facility in Karachi, Pakistan, Cureus. Vol. (10), no. (11), pp. 1-6.

24. Naved S., Siddiqui S., \& Khan F., (2011): APACHE-II Score Correlation With Mortality And Length Of Stay In An Intensive Care U nit, Journal of the College of Physicians and Surgeons Pakistan, Vol. (21), no. (1), pp. 4-8.

25. Nishijima K., Simel L., Wisner H., Holmes F., (2012): Does this adult patient have a blunt intraabdominal injury?, JAMA, vol.(307), no. (14), pp. 1517-27.

26. Ntundu S., Herman A., Kishe A., Babu H., Jahanpour O., Msuya D., Chugulu S., \& Chilonga K., (2019): Patterns and outcomes of patients with abdominal trauma on operative management from northern Tanzania: a prospective single centre observational study, BMC Surgery, vol. (19), no. (69), pp. 1-10.

27. Ohene M., Dakubo J., Boakye F., \& Naeeder S., (2010): Penetrating abdominal injuries in adults seen at two teaching hospitals in Ghana, Ghana Med J, vol. (44), no. (3), pp. 103- 108.

28. Olaogun J., Akute O., Etonyeaku A., Ige A., Ajibola D., Afolayan J., \& Emmanuel E., (2018): Abdominal trauma in a semi-urban tertiary health institution , Journal Emergency Practice and Trauma, vol. (4), Issue (2), pp. 67-72.

29. Panchal H., \& Ramanuj A., (2016): The study of abdominal trauma: patterns of injury, clinical presentation, organ involvement and associated injury, Int Surg J. vol. (3), no. (3), pp.1392-1398
30. Pillai J., Isaac A., Kandasamy N., \& Lewi D., (2015): Clinical applications of the Injury Severity Scoring system (ISS): The clinical, radiological, educational, research and economic implications on reporting in trauma. Results from a tertiary trauma centre in UK., Conference: European Radiology Congress At: Vienna, Pp. 1:8

31. Rajaei S., Taziki H., Keshtkar A., \& ShoaKazemi A., (2012): Prevalence of intra abdominal injuries due to penetrating trauma in Gorgan, Iran (2002-07). J Gorgan Uni Med Sci, vol. (14), no. (2), pp. 97-100.

32. Shojaee M., Faridaalaee G., Yousefifard M., Yaseri M., Dolatabadi A., Sabzghabaei A., \& Malekirastekenari A., (2014): New scoring system for intra-abdominal injury diagnosis after blunt trauma, Chinese Journal of Traumatology, vol. (17), no. (1), pp.19-24.

33. Urden L., Stacy K., \& Lough M., (2018): Critical care nursing diagnosis and management $8^{\text {th }}$ edition, chapter 8: Trauma, $\mathrm{P}$ 790.

34. Vanitha T., (2018): Prospective Study Comparing The Clinical Abdominal Scoring System (Cass) With Blunt Abdominal Trauma Severity Scoring (Batss) In Predicting The Necessity of Laparotomy, IOSR Journal of Dental and Medical Sciences (IOSR-JDMS), Vol. (17), Issue (3), pp. 25-33

35. Weledji P., \& Tambe J., (2018): Perspectives on the Management of Abdominal Trauma, Vol.(6), No.(2:1), pp. 1: 7. 